\title{
Operative Fixation of Displaced Middle Third Clavicle (Edinburg Type 2) Fracture with Superior Reconstruction Plate Osteosynthesis
}

\author{
Dhoju D, Shrestha D, Parajuli NP, Shrestha R, Sharma V
}

Department of Orthopaedics and traumatology

Kathmandu University School of Medical Sciences

Dhulikhel Hospital- Kathmandu University Hospital

Dhulikhel, Nepal

Corresponding Author

Darshan Dhoju

Department of Orthopaedics and traumatology

Kathmandu University School of Medical Sciences

Dhulikhel Hospital- Kathmandu University Hospital

Dhulikhel, Nepal

Email: docdhoju@hotmail.com

\section{Citation}

Dhoju D, Shrestha D, Parajuli N, Shrestha R, Sharma V. Operative Fixation of Displaced Middle Thirrd Clavicle (Edinburg Type 2) Fracture with Superior Reconstruction Plate Osteosynthesis. Kathmandu Univ Med J 2011;36(4):286-91.

\begin{abstract}
Background

Conservative management of middle third clavicle fracture has been recently reported with suboptimal outcomes. Despite higher nonunion rates in initial open reduction and internal fixation, understanding the problem better and taking in accounts of previous shortcomings, such fractures can be optimally treated by open reduction and internal fixation with reconstruction plate.
\end{abstract}

\section{Objective}

To study the outcome of middle third clavicle fracture treated with superior reconstruction plating in terms of function using Constant shoulder score, union time and rate, complications and patient satisfaction.

\section{Methods}

Twenty patients with displaced middle third clavicle fracture (Edinburg type 2) treated with open reduction and internal fixation with reconstruction plate implanted in superior surface were prospectively followed for at least one year after surgery.

\section{Results}

There were 20 patients, 16 males and 4 females. The mean age of the patients was 31.5 years with SD 11.5 years (range $15-60$ years) and 5 patients (25\%) had associated injuries. All fractures united in 16 weeks or less in near anatomic position with complication in 2 (5\%) patients, one deep infection and one frozen shoulder which on subsequent management recovered well. There was no nonunion or implant failure. The average Constant score was 97.45 in one year follow up and the patients were relatively satisfied with the treatment.The most common indication $(25 \%)$ for hardware removal was young age of the patient, hardware prominence and occasional discomfort

\section{Conclusion}

This small series shows that displaced midshaft clavicle fracture can be optimally treated with operative fixation implanting the reonstruction plate in superior surface with six cortical purchases on either side and supervised physiotherapy, although subsequent surgery for implant removal might be necessary.

\section{KEY WORDS}

middle third clavicle fracture, reconstruction plate.

\section{INTRODUCTION}

The consensus of management is inclining towards open reduction and internal fixation for displaced middle third clavicle fractures (Edinburg type 2), as the conservative management gives poor results. ${ }^{1}$ Until recently, there was no evidence to suggest that early operative treatment of displaced clavicular shaft fractures conferred a functional benefit when compared with the results of initial nonoperative treatment. ${ }^{2-6}$ However, recent studies show initial shortening of two $\mathrm{cm}$ was associated with greater risk of nonunion, poor clinical outcome, and decrease in 
shoulder strength and endurance. ${ }^{7,8}$

Various methods have been described for operative fixation of clavicular shaft fractures, implants including extramedullary semitubular plates, reconstruction plates, Dynamic Compression Plate(DCP), Limited Contact Dynamic Compression Plate (LCDCP), locking plates, external fixator or intramedullary fixation with $\mathrm{K}$ wire, Knowle's pins, Haige pins, Rockwood pins and titanium nails.

Intramedullary fixation of calvicle, though more cosmetic is technically more demanding owing to lack of clear cut medullary canal and higher complication rates upto $75 \% .{ }^{9}$ Plate fixation provides immediate rigid stabilization, pain relief, facilitates early mobilisation and return to pre injury activities. ${ }^{2,7,10}$ Superior placement of plate is biomechanically more stable especially in presence of inferior cortical communition. ${ }^{11}$ So, Open Reduction and Internal Fixation (ORIF) with superior recon plating was preferred in adults with displaced middle third clavicle fracture and those having tenting skin. ${ }^{4}$ The aim of this study is to evaluate the functional outcome of midshaft clavicular fracture in adults managed with ORIF with superior reconstruction plating.

\section{METHODS}

Twenty patients with displaced middle third clavicle fracture who underwent open reduction and internal fixation with superior reconstruction plating in Dhulikhel hospital between Feb 2008 to Jan 2011 were prospectively followed. Permission from institutional review committee and patient was obtained. Demographic variables, mode of injury, injury-surgery interval, hospital stay, time required for union, and need for secondary procedures were recorded. Fracture was classified according to Edinburgh system. ${ }^{1}$ Elderly patients, skeletally immature and patients with open fracture, pathological fracture, associated ipsilateral multiple fracture were excluded.

\section{Surgical technique}

All operations were performed under general anaesthesia (GA). All patients were put in supine position with a bolster in interscapular space and upper extremity in the involved side was disinfected and drappped free for mobilisation.

A relatively curved incision was given over the superior aspect of clavicle. Supraclavicular nerve was identified and attempted to preserve, but was sacrified in some cases hindering operation. The fracture site was exposed and outmost respect was paid to avoid excess periosteal stripping. Reduction was done and fracture was stabilized by contoured $3.5 \mathrm{~mm}$ reconstruction plate placed superiorly with at least 6 cortical purchases on either side. Cancellous screws were used as necessary at the lateral end for better purchase in cancellous bone. Interfragmentary screw and bone graft was done as thought required. Incision was closed in two layers. Intercutaneous closure of skin was done with 4-0 monosyn. The limb was supported with arm pouch post operatively.

\section{Post operative protocol}

Wound was inspected on second day and patient discharged home on second or third post operative day if the wound was satisfactory. On two weeks follow up, the sutures was removed and check $x$-ray done. Patient was advised for gentle pendulum exercise only. Next follow up was done in six weeks, where repeat X-ray was done and full range of motion of shoulder started. Subsequent follow up was done in three months, six months and one year. Those with unsatisfactory callus formation in three months were called at monthly interval for repeat X-ray till union occured. Union was considered if clinically the fracture site was non tender, no abnormal movement and radiologically when there was visible callous.

In one year follow up, the patients were counseled about implant removal and final functional outcome was evaluated using Constant score and patient's satisfaction.

\section{RESULTS}

Demographic profiles and outcome of each case are tabulated in table 1.

There were 20 patients, 16 males and 4 females. The mean age of the patients was 31.5 years with SD 11.5 years (range 15-60 years). Eleven fractures occurred on the right and nine on the left side, nine resulting from fall from height, 10 due to RTA and one due to buffalo assault. According to Edinburg system, 12 were type $2 \mathrm{~A} 2$, five were $2 \mathrm{~B} 1$ and three were $2 \mathrm{~B} 2$ fracture. Five fractures had tenting skin and none had open fracture, associated neurovascular injury or scapulothoracic dissociation. Five patients (25\%) had associated injuries, three had rib fracture and one had metacarpal and remaining one had tibia fracture and fracture of multiple phalanges of foot. Associated injuries besides rib fracture were managed in the same operative setting. One patient had surgical emphysema and surgery was performed after five days as the patient had impending skin perforation (case seven). Two cases had previous fixation with rush pin, but resurgery with plating was done due to early migration of rush pin (case3,17). Reconstruction plate $(3.5 \mathrm{~mm})$ ranging from seven to nine holes was used and contoured as necessary. Interfragmentary screw was applied in four cases and primary bone graft was done in two cases. The average hospital stay was 3.9 days. All the patients were operated on the next day of admission except two (case 7,18 ) as one had surgical emphysema and the other with associated tibia fracture developed early signs of fat embolism. These cases were operated on fifth and $14^{\text {th }}$ day post injury respectively.

All the cases were operated on the next day of injury besides two cases which presented with complication of previous intramedullary rush pin fixation and another two with associated injuries demanding delay in surgery. None of the patients had early wound infection. One patient had deep infection in 5 months follow up and the implant was 
Table 1. Patients and injury data.

\begin{tabular}{|c|c|c|c|c|c|c|c|c|c|c|c|}
\hline SN & Age & Sex & $\begin{array}{l}\text { Injury treat- } \\
\text { ment interval } \\
\text { (days) }\end{array}$ & $\begin{array}{l}\text { Hospi- } \\
\text { tal stay } \\
\text { (days) }\end{array}$ & Side & $\begin{array}{l}\text { Edinburg } \\
\text { type }\end{array}$ & $\begin{array}{l}\text { Mode of } \\
\text { injury }\end{array}$ & Associated injuries & Complications & $\begin{array}{l}\text { Constant } \\
\text { Score }\end{array}$ & $\begin{array}{l}\text { Implant } \\
\text { removal }\end{array}$ \\
\hline 1 & 33 & M & 1 & 3 & $\mathrm{Rt}$ & $2 \mathrm{~A} 2$ & fall & & & 96 & \\
\hline 2 & 38 & M & 1 & 4 & Lt & $2 \mathrm{~A} 2$ & fall & $4 / 5 \mathrm{rib} \#$ & & 95 & yes \\
\hline 3 & 35 & $\mathrm{~F}$ & 25 & 4 & $\mathrm{Lt}$ & 2B1 & fall & & & 98 & \\
\hline 4 & 26 & M & 1 & 7 & Lt & $2 \mathrm{~B} 2$ & RTA & $3^{\text {rd }} \mathrm{MC} \#$ & & 100 & \\
\hline 5 & 24 & M & 1 & 1 & Lt & $2 \mathrm{~A} 2$ & RTA & & & 100 & \\
\hline 6 & 24 & $\mathrm{MF}$ & 2 & 2 & $\mathrm{Rt}$ & $2 \mathrm{~A} 2$ & RTA & & & 98 & yes \\
\hline 7 & 60 & M & 5 & 5 & $\mathrm{Rt}$ & $2 \mathrm{~A} 2$ & fall & surgical emphysema & frozen shoulder & 90 & \\
\hline 8 & 25 & M & 1 & 4 & $\mathrm{Rt}$ & $2 \mathrm{~A} 2$ & fall & & & 100 & \\
\hline 9 & 24 & $\mathrm{~F}$ & 1 & 4 & Lt & $2 \mathrm{~B} 2$ & RTA & & & 100 & yes \\
\hline 10 & 35 & $M$ & 1 & 4 & $\mathrm{Lt}$ & $2 \mathrm{~A} 2$ & fall & & & 98 & \\
\hline 11 & 18 & $M$ & 1 & 5 & $\mathrm{Lt}$ & $2 \mathrm{~A} 2$ & RTA & $3 / 4$ rib \# & deep infection & 90 & \\
\hline 12 & 40 & $M$ & 1 & 3 & $\mathrm{Rt}$ & 2B1 & RTA & & & 95 & \\
\hline 13 & 30 & $M$ & 1 & 4 & $\mathrm{Rt}$ & $2 \mathrm{~B} 1$ & RTA & & & 100 & \\
\hline 14 & 32 & M & 1 & 3 & $\mathrm{Rt}$ & $2 \mathrm{~A} 2$ & $\begin{array}{l}\text { buffalo } \\
\text { assault }\end{array}$ & & & 98 & yes \\
\hline 15 & 15 & $\mathrm{~F}$ & 1 & 4 & $\mathrm{Lt}$ & $2 \mathrm{~A} 2$ & fall & & & 100 & \\
\hline 16 & 18 & M & 1 & 3 & $\mathrm{Lt}$ & $2 A 2$ & fall & & & 100 & \\
\hline 17 & 35 & $M$ & 30 & 2 & $\mathrm{Rt}$ & $2 \mathrm{~B} 1$ & RTA & & & 95 & \\
\hline 18 & 27 & M & 1 & 10 & $\mathrm{Rt}$ & $2 \mathrm{~A} 2$ & RTA & Rt tibia \# & & 98 & yes \\
\hline 19 & 57 & M & 3 & 3 & $\mathrm{Rt}$ & 2B1 & fall & & & 98 & \\
\hline 20 & 35 & $M$ & & 3 & $\mathrm{Rt}$ & 2B1 & RTA & & & 100 & \\
\hline
\end{tabular}

removed. However the fracture had already united and the infection was only in the screw holes. Careful curettage was done and was treated as chronic osteomyelitis. One patient developed frozen shoulder in three months follow up where Manipulation under anesthesia (MUA) was done in four months and put under extensive physiotherapy. Subsequent follow up was unremarkable.

All the fractures had united in near anatomic position on four months follow up. Implants were removed in five patients after one year, the most common indication being hardware prominence and young age. The average constant score was 97.45 with SD 3.1 in one year follow up. All the patients were relatively satisfied with the procedure. None of the patients had implant loosening, non union or implant failure.

In 12 cases (60\%), the supraclavicular nerve was transected either during initial plating or implant removal as it hindered the operation considerably, but none of the patients had any complaints on subsequent follow up.

\section{DISCUSSION}

Fractures of the clavicle are common, accounting for $2.6 \%$ of all fractures, more than $75 \%$ located in the midshaft. ${ }^{12}$

Many conservative treatment methods have been described, but simple arm sling or figures of 8 bandage have been widely used. ${ }^{13}$ Neither technique reduces the fracture, the outcomes were identical, but arm sling demonstrated better patient satisfaction. ${ }^{14}$ Moreover, figure of eight bandage was associated with higher complications like axillary pressure sore, neurovascular compression. ${ }^{14}$ Past studies have shown high level of patient satisfaction after non operative treatment of these fractures and even more operative treatment had higher rates of nonunion. ${ }^{4,15-17}$ However, recent studies have demonstrated higher rates of nonunion and poor functional outcomes after nonoperative treatment, while the results of primary operative treatment have improved considerably. ${ }^{8,18,19}$ The deforming force of sternocledomastoid is very strong and cannot be overcome by external supports provided by arm sling or figure of eight bandage. ${ }^{20}$

Neer's nonunion rate of $1 \%$ is misleading as more recent studies show higher rates of nonunion in displaced midshaft clavicle fracture treated conservatively. ${ }^{15}$ It was 4.5 to $9.5 \%$ in Robinson's series, $15 \%$ in Hill's series, and $13 \%$ in White et al study, when such fractures were managed conservatively. ${ }^{1,7,21}$ Moreover, shortening $>2 \mathrm{~cm}$ and overlapping leads to greater risk of nonunion, more pain, poor cosmetic and functional results. ${ }^{7,8,22}$ A metanalysis of recent studies reduced the risk of nonunion by $86 \%$ in the operative group compared to non operative group. ${ }^{9}$ Drawbacks of conservative management can be effectively overcome by surgically treating these fractures achieving near normal anatomic, cosmetic and functional profile. ${ }^{8,18}$ 


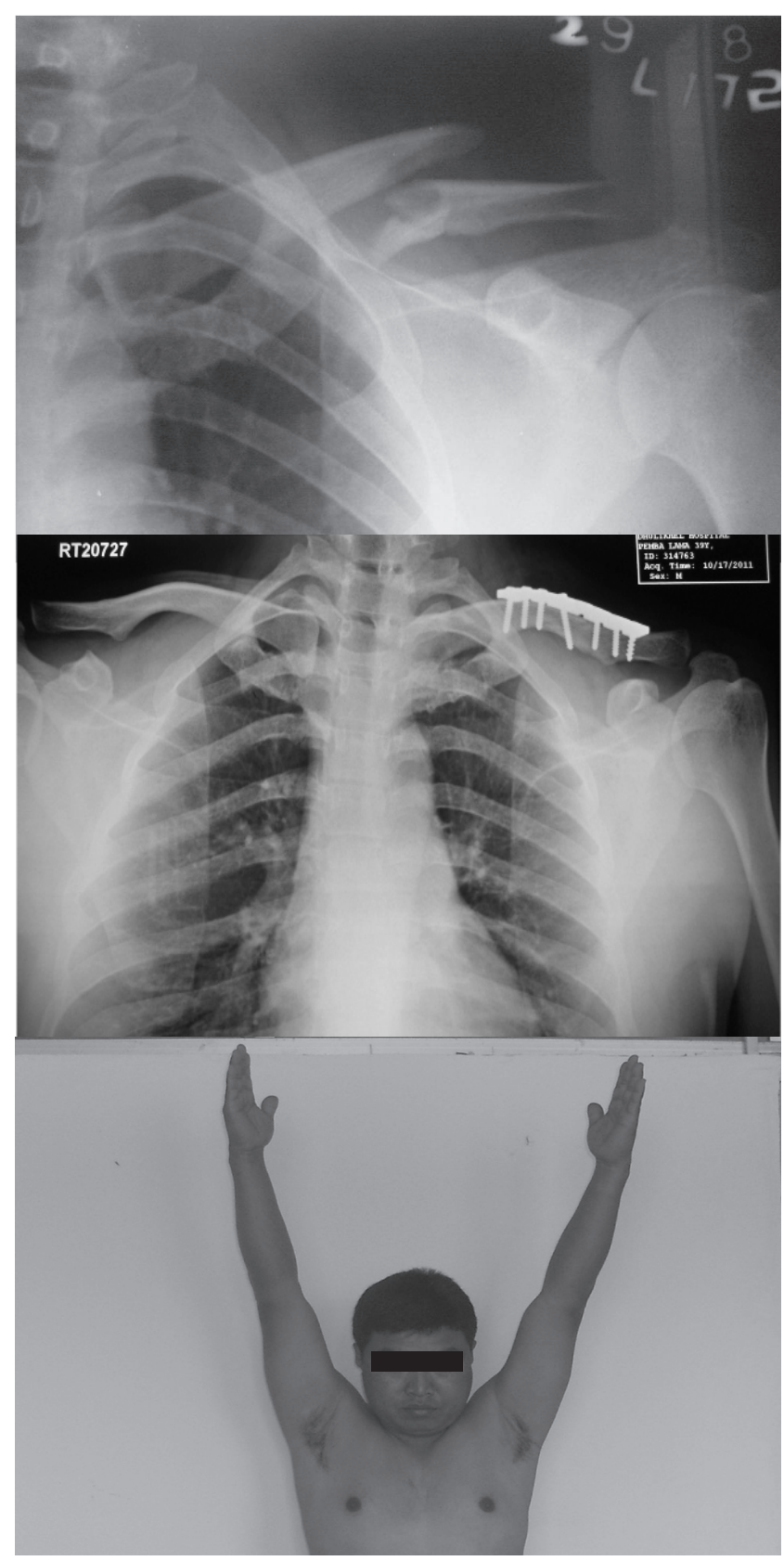

Figure 1. a. Edinburg type 2B1 fracture of left clavicle, b. Healed fracture in 16 weeks follow up, note interfragmentary screw, c. Normal abduction in 1 year follow up.

Plate fixation provides immediate rigid stabilization, pain relief, facilitates early mobilisation and return to pre injury activities. ${ }^{2,7,10}$ Superior placement of plate is biomechanically more stable especially in presence of inferior cortical communition, but associated with greater risk of injury to underlying neurovascular structures and subsequent prominence of plate may necessitate its removal. ${ }^{11}$ Low complication rate was associated with inferior implantation of plate, although superior placement provided biomechanically more secure fixation. ${ }^{11}$ In our series also stability was preferred over cosmesis and fracture was fixed with superior implantation of reconstruction plate countering it as necessary. Neer and Rowe's higher rate of nonunion after operative fixation can be overcome by using $3.5 \mathrm{~mm}$ reconstruction plate with

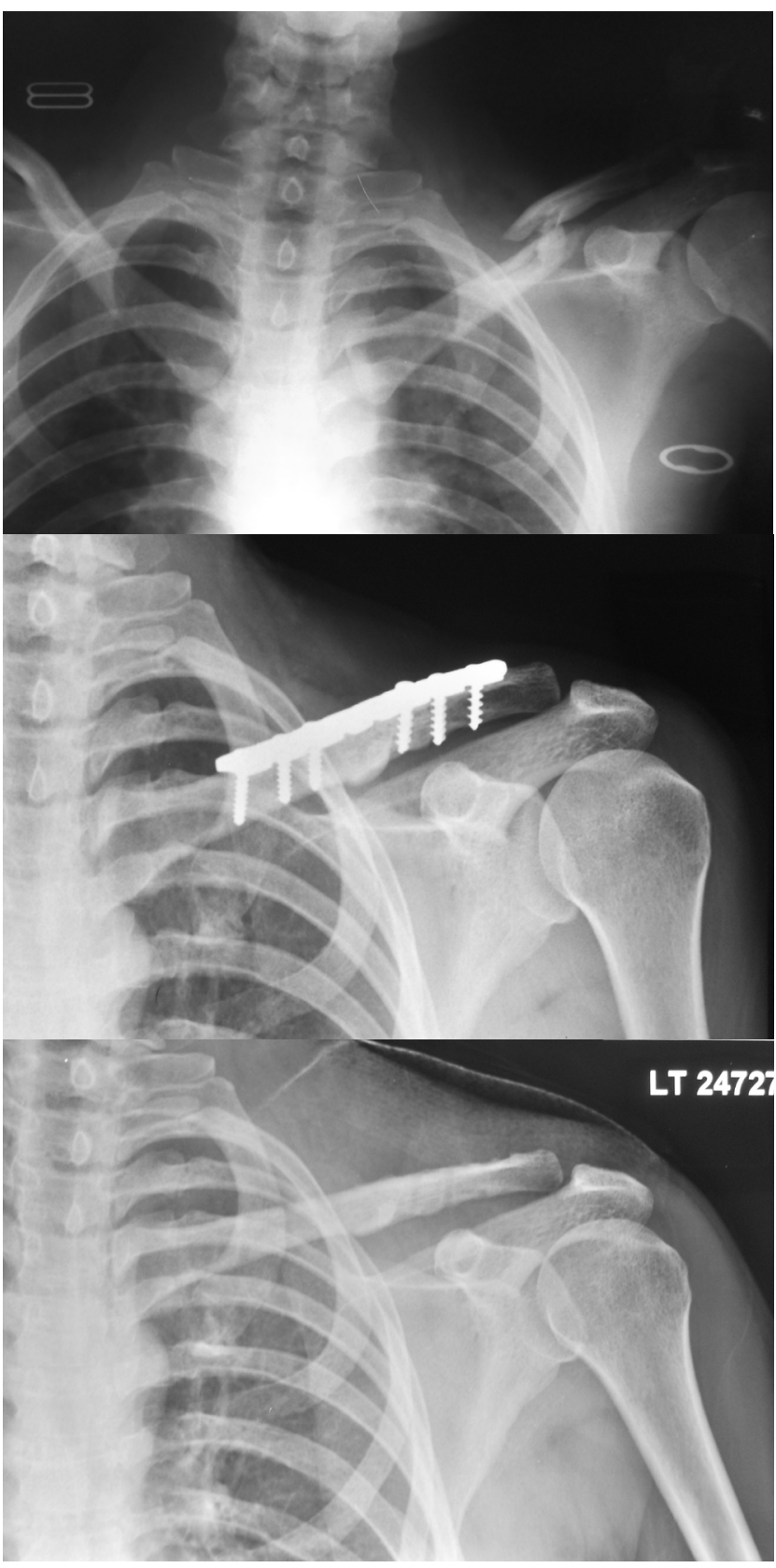

Figure 2. a. Edinburg type 2B1 Left clavicle fracture, b. Healed fracture, c. Implant removal after 1 year.

at least six cortical purchase on either side and delaying institution of physiotherapy programme.,12 A recent multicentre trial comparing non operative treatment with primary plate fixation for displaced fractures in 138 patients demonstrated better functional outcomes, lower rates of maluion and nonunion, and a shorter time to union in the latter group. ${ }^{18}$ Constant score significantly improved in operative group and the mean time to radiographic union was 38.4 weeks in non operative group compared with 16.4 weeks in operative group (p-0.001)29. ${ }^{18,23}$ In our series also, there was no maluion or nonunion, excellent function with average Constant score of 97 and all fractures united in 16 or less weeks. Clinical and radiographic signs of nonunion included mobility or pain on stressing of the fracture and an absence of bridging callus on radiographs. ${ }^{3}$ 
Interfragmentary screw provides compression at fracture site but should be applied carefully as it might cause more communition. In our series, we applied such screws in 4 cases, but communition occurred in two, so was avoided in latter cases. Primary bone graft may be indicated in communited fracture and was done in two type 2B2 fractures, which healed uneventfully.

Although the complication rate of $34 \%$ and a re-operation rate of $18 \%$ (most for hardware removal) are reported in operative group, in our series we encountered complications in two(10\%) cases and five( $25 \%$ ) reoperations all for implant removal. ${ }^{18}$ The complications related to plate fixation are infection, plate failure, hypertrophic or dysesthetic scars, implant loosening, non union, and rarely intraoperative

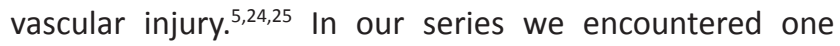
deep infection requiring early implant removal and one frozen shoulder which recovered well after MUA and extensive physiotherapy. No early complications occurred after implant removal. Though it is important to preserve supraclavicular nerve during operation, none of our patients had any complaints even if it was sacrificed during operation.

\section{REFERENCES}

1. Robinson $\mathrm{CM}$. Fractures of the clavicle in the adult. Epidemiology and classification. J Bone Joint Surg Br 1998;80:476-84.

2. Neer CS 2 nd. Fractures of the distal third of the clavicle. Clin Orthop Relat Res 1968;58:43-50.

3. Robinson $\mathrm{CM}$, Court-Brown $\mathrm{CM}$, McQueen MM, Wakefield AE. Estimating the risk of nonunion following nonoperative treatment of a clavicular fracture. J Bone Joint Surg Am 2004;86:1359-65.

4. Rowe CR. An atlas of anatomy and treatment of midclavicular fractures. Clin Orthop Relat Res 1968;58:29-42.

5. Böstman $\mathrm{O}$, Manninen $\mathrm{M}$, Pihlajamäki $\mathrm{H}$. Complications of plate fixation in fresh displaced midclavicular fractures. I Trauma 1997; 43:778-83.

6. Zenni EJ Jr, Krieg JK, Rosen MJ. Open reduction and internal fixation of clavicular fractures. J Bone Joint Surg Am 1981;63:147-51.

7. Hill JM, McGuire MH, Crosby LA. Closed treatment of displaced middle-third fractures of the clavicle gives poor results. J Bone Joint Surg Br 1997;79:537-9.

8. McKee MD, Pedersen EM, Jones C, Stephen DJ, Kreder HJ, Schemitsch EH, Wild LM, Potter J. Deficits following nonoperative treatment of displaced midshaft clavicular fractures. I Bone Joint Surg Am 2006;88:35-40.

9. Zlowodzki M, Zelle BA, Cole PA, Jeray K, Mckee MD; Evidence-Based Orthopaedic Trauma Working group. Treatment of midshaft clavicle fractures: systematic review of 2144 fractures: on behalf of EvidenceBased Orthopaedic Trauma Working group. I Orthop Trauma 2005; 19:504-7.

10. Mullaji $A B$, Jupiter JB. Low-contact dynamic compression plating of the clavicle. Injury 1994;25:41-5.

11. lannotti MR, Crosby LA, Stafford P, Grayson G, Goulet R. Effects of plate location and selection on the stability of midshaftclavicle osteotomies: a biomechanical study. J Shoulder Elbow Surg 2002;11:457-62.

12. Crenshaw AH. Fractures of the shoulder girdle arm and forearm. In: Crenshaw AH, editor. Campbell's operative orthopaedics. 8th ed. St.Louis: Mosby Year book; 1992.p 989-1053.

\section{CONCLUSION}

The traditional method of managing middle third clavicular fracture conservatively gives poor functional results. Intramedullary fixation is not favored for its higher complication rate though better cosmesis. Reconstruction plates can be contoured according to the need and superior placement with six cortical purchases on either side gives stable construct, predictable union and optimum functional outcome. Use of bone Interfragmentary screws should be done carefully as might cause further communition and primary bone graft might be justified in communited fractures. Owing to the subcutaneous anatomy of clavicle, superior implantation of implant might cause hardware prominence especially in lean individuals demanding subsequent removal. Site specific precontoured locking plates in recent use are yet to be fully tested in comparative clinical studies.

13. Lester $\mathrm{CW}$. The treatment of fractures of the clavicle. Ann Surg 1929;89:600-6.

14. Andersen K, Jensen PO, Lauritzen J. Treatment of clavicular fractures. Figure-of-eight bandage versus a simple sling. Acta Orthop Scand 1987;58:71-4.

15. Neer CS 2nd .Nonunion of the clavicle. JAm Med Assoc 1960;172:100611.

16. Eskola A, Vainionpää $S$, Myllynen $P$, Pätiälä $H$, Rokkanen P. Outcome of clavicular fracture in 89 patients. Arch Orthop Trauma Surg 1986;105:337-8.

17. Nordqvist A, Petersson CJ, Redlund-Johnell I. Mid-clavicle fractures in adults: end result study after conservative treatment. $J$ Orthop Trauma 1998;12:572-6.

18. Canadian Orthopaedic Trauma Society. Nonoperative treatment compared with plate fixation of displaced midshaft clavicular fractures. A multicenter, randomized clinical trial. J Bone Joint Surg Am 2007;89:1-10.

19. Wun-Jer Shen, Tsung-Jen Liu, Young-Shung Shen. Plate fixation of fresh displaced midshaft clavicle fractures. Injury 1999; 30:497-500.

20. Poigenfurst J, Rappold G, Fischer W. Plating of fresh clavicular fractures: results of 122 operations. Injury 1992; 23(4):237-41

21. White RR, Anson PS.Adult Clavicle fractures: relationship between mechanism of injury and healing. Orthop Trans 1989; 13:514-5.

22. Eskola A, Vaininpaa S. Surgery for ununited clavicle fracture. Acta Orthop Scand 1986; 57:300-70.

23. Consent CR, Murley AH. A Clinical method of functional assessment of the shoulder .clin Orthop Relat Res !987;214:160-

24. Poigenfürst J, Rappold G, Fischer W. Plating of fresh clavicular fractures: results of 122 operations. Injury 1992;23:237-41. 4

25. Freeland A. Unstable adult midclavicular fracture. Orthopedics 1990;13:1279-81. 